\title{
25 Research Soure \\ The Burden of Orthopaedic Disease in Sub-Saharan Africa: A Focus on Tanzania
}

\section{William Mack Hardaker ( $\nabla$ tuh31479@temple.edu )}

Temple University School of Medicine: Lewis Katz School of Medicine at Temple University

Mubashir Jusabani

Kilimanjaro Christian Medical Centre

Honest Massawe

Kilimanjaro Christian Medical Centre

Anthony Pallangyo

Kilimanjaro Christian Medical Centre

\section{Rogers Temu}

Kilimanjaro Christian Medical Centre

Gileard Masenga

Kilimanjaro Christian Medical Centre

Nathaniel Fessehaie

University of Pennsylvania Perelman School of Medicine

Anchi Numfor

University of Pennsylvania Perelman School of Medicine

Matthew Winterton

University of Pennsylvania Perelman School of Medicine

Ajay Premkumar

Hospital for Special Surgery

Neil Sheth

University of Pennsylvania Perelman School of Medicine

\section{Research}

Keywords: Road Traffic Trauma, Epidemiology, Trauma, Injury, Global Orthopaedics

Posted Date: April 8th, 2021

DOI: https://doi.org/10.21203/rs.3.rs-402380/v1

License: (c) (1) This work is licensed under a Creative Commons Attribution 4.0 International License. Read Full License 


\section{Abstract}

Background As road traffic crashes (RTCs) continue to rise in the developing world, the current growth rate and true burden of orthopaedic injuries are unknown. In 2015, we characterized the orthopaedic burden at Kilimanjaro Christian Medical Center (KCMC) in Tanzania. In this study, we re-evaluated the burden and growth-rate over three years in the absence of any system level changes. Additionally, we calculated the percentage of orthopaedic patients that received definitive fixation for their orthopaedic injury when surgery was indicated.

Methods We prospectively collected data for 190 patients admitted to the orthopaedic ward at KCMC during June/July 2018. We also retrospectively reviewed available records for patients presenting to the KCMC emergency department, orthopaedic outpatient clinic and orthopaedic ward.

Results Prospective data: RTC (48.6\%) was the most common etiology and femur fractures (31.0\%) the most common type of injury. Almost $96 \%$ of admitted patients were indicated for surgical fixation, but only $44.5 \%$ received definitive fracture treatment. Retrospective data: KCMC treated an average of 15,117 orthopaedic patients per year, representing a 35.3\% growth in the orthopaedic burden compared to 2015 .

Conclusion The burden of orthopaedic surgical disease at KCMC continues to grow. Throughout the developing world, multiple system level constraints preclude delivery of definitive treatment for most patients. Without innovative strategies to address this situation, the discrepancy between the need for orthopaedic care and surgical care capacity in the developing world will continue to grow.

\section{Background}

The burden of musculoskeletal disease in low- and middle-income countries (LMIC) continues to increase mainly due to road traffic crashes (RTC). Globally, RTCs constitute over 1.35 million deaths annually more deaths than HIV/AIDS, tuberculosis and diarrheal diseases combined, and represent the third leading cause of disability for people aged 15-44. $(1,2)$ Traumatic musculoskeletal injuries often necessitate orthopaedic surgical treatment. However, in LMICs, even at tertiary referral centers, definitive care is not readily accessible for most patients.

Countries in Sub-Saharan East-Africa are no exception to this scenario. In 2017, Tanzania experienced 17,840 deaths due to RTCs, the 9th highest mortality rate from RTCs worldwide.(2) For its population of almost 50 million people, there are 45 consultant orthopaedic surgeons; only one orthopaedic surgeon for every 1.1 million Tanzanians.(3) Given this massive discrepancy, the current workforce is unable to address the demand for orthopaedic services.

Our group previously characterized the orthopaedic burden at Kilimanjaro Christian Medical Center (KCMC) in northern Tanzania. At this tertiary referral center, the orthopaedic volume is comparable to that of a level one trauma center in the United States of America (USA), and only $10 \%$ of the catchment area population have access to orthopaedic surgical care. $(4,5)$ As RTCs continue to rise in the developing 
world, the current growth rate and true burden of orthopaedic injuries is still unknown.(1) In this study, we calculated the percentage of orthopaedic patients that received definitive fixation for their orthopaedic injury when surgery was indicated. We also re-evaluated KCMC's orthopaedic burden and documented the growth-rate since 2015 in the absence of any system level changes. We hypothesized that the number of patients that received definitive treatment of their musculoskeletal injury would be less than previously reported and that the burden of disease at KCMC would grow considerably over a three-year period.

\section{Methods}

\section{Setting}

KCMC is a 700-bed facility in northern Tanzania and is one of the country's four large tertiary referral centers. Its catchment area covers 12.5 million people from five surrounding regions (Fig. 1). Each year, the institution treats 110,000 outpatients and admits approximately 25,000 patients for inpatient care. KCMC has limited material and personnel resources, including just four full-time equivalent orthopaedic surgeons, 17 orthopaedic residents and 16 trained nurses (equating to three nurses per shift). The orthopaedic ward consists of 66 total beds: three 12-bed rooms, three 4-bed rooms, four 2-bed "private" rooms, and one 10-bed pediatric room. There are five operating theaters of which only one is dedicated to orthopaedic surgery. A second operating theater is shared with the general surgery and obstetrics and gynecology departments and is used approximately twice weekly for septic orthopaedic cases. There is one full-time anesthesiologist and 11 nurse anesthetists shared between all departments across the five operating theaters. There is no established pre-hospital emergency response system in northern Tanzania, and most patients reach the hospital via personal transportation or ambulance reserved for inter-facility transfer of critically ill patients.(4)

\section{Study Design}

We prospectively collected data for all patients admitted to the orthopaedic ward at KCMC from June 2018 to July 2018(4). We also retrospectively reviewed all available records for patients presenting to the KCMC emergency department (ED), orthopaedic outpatient clinic and orthopaedic ward (Table 1). This study received KCMC Clinical Research Ethical Review Committee approval prior to data collection and analysis.

Table 1 Retrospective Data Sources and Study Periods

\begin{tabular}{|c|c|c|}
\hline Patient Record Type & Time Period & Dates \\
\hline Emergency Department & $\begin{array}{l}\text { Seven consecutive } \\
\text { months }\end{array}$ & October 1, 2017 - April 30, 2018 \\
\hline $\begin{array}{l}\text { Orthopaedic Outpatient Clinic } \\
\text { Orthopaedic Ward } \\
\text { Admissions }\end{array}$ & $\begin{array}{l}81 \text { consecutive clinic days } \\
31 \text { consecutive months }\end{array}$ & $\begin{array}{l}\text { April 10, } 2018 \text { - August 1, } 2018 \\
\text { January 1, } 2016 \text { - July 31, } 2018\end{array}$ \\
\hline
\end{tabular}

\section{Data Collection}


All patients, except those with isolated spine injuries, admitted to the orthopaedic ward during the sixweek study period were included for prospective data collection (Table 2). When available, admission and post-operative radiographs were collected and reviewed by two senior orthopaedic surgery resident authors (AP and CP). The authors classified each admission radiograph according to the 2018 AO/OTA Fracture and Dislocation Guidelines and determined if surgical fixation was indicated.(6) Post-operative radiographs were evaluated for the presence of definitive surgical fixation. Patients who received open reduction and internal fixation (ORIF) or intramedullary nailing were categorized as having undergone definitive surgical fracture treatment; cases for which external fixation was used as definitive treatment were individually assessed for appropriateness. Implant removal procedures were also categorized as definitive treatment.

Table 2

Data Collected - Prospective Admissions

\begin{tabular}{|l|}
\hline Age \\
\hline Sex \\
\hline Region of residence \\
\hline Occupation \\
\hline Mechanism of injury \\
\hline Diagnosis \\
\hline Fracture location \\
\hline Fracture type (open vs. closed) \\
\hline Pre-operative treatment (skeletal traction, casting, splint, etc.) \\
\hline Surgery provided \\
\hline Time to surgery \\
\hline Hospital length of stay \\
\hline Admission and post-operative radiographs (as available) \\
\hline
\end{tabular}

\section{Retrospective Data}

All available ED, outpatient clinic and orthopaedic ward records were reviewed by two authors (WH and $\mathrm{MJ}$ ). Review of ED records established the total number of orthopaedic consultations. Outpatient analysis determined the total number of evaluated clinic patients and the percentage of patients presenting with health insurance. Retrospective review of orthopaedic ward data determined the number of ward admissions, diagnoses and discharge status (including deaths). Deaths were cross-referenced with hospital mortality reports. 


\section{Statistical Analysis}

Statistical analysis was performed using the R: a language and environment for statistical computing ( $R$ Foundation for Statistical Computing, http://www.R-project.org). Student t-tests were performed for continuous data and $\chi^{2}$ or Fisher exact tests were performed for categorical data. Two-tailed $p$ values < 0.05 were considered statistically significant. Cohen's Kappa statistic was calculated to assess interobserver agreement of prospective definitive treatment designations and inter-observer agreement of retrospective data abstraction.

\section{Results}

\section{Prospective Cohort}

During the study period, 231 patients were admitted to the orthopaedic ward. Forty-one (17.7\%) isolated spine patients were excluded, leaving 190 patients in the final study cohort. The majority of admitted patients were male and under the age of 45 years (Table 3). Males tended to be younger (mean age 37.8, range 3 to 98 years, SD 23.7) than females (mean age 43.9, range 2 to 94 years, SD 21.5) $(p=0.108)$. (data not shown) The most common occupations were farmer, businessman and student, which together accounted for over $50 \%$ of patient reported jobs. Of the 190 patients prospectively followed during the sixweek study period, 138 (72.6\%) were discharged home, 45 (23.7\%) were still admitted at the end of the data collection period and seven (3.7\%) died as an inpatient. 
Table 3

Demographic Data (Age, Sex, Occupation) $(\mathrm{n}=$ 190)

\begin{tabular}{|lll|}
\hline Variable & $\mathbf{n}$ & $\%$ \\
\hline Age, years & & \\
\hline $0-14$ & 23 & 12.1 \\
\hline $15-44$ & 104 & 54.7 \\
\hline $45-64$ & 37 & 19.5 \\
\hline More than 64 & 26 & 13.7 \\
\hline Age, years, mean (SD) & $39.2(22.1)$ & \\
\hline Sex, male & 147 & 77.4 \\
\hline Occupation & & \\
\hline Farmer & 38 & 20.0 \\
\hline Business & 31 & 16.3 \\
\hline Student & 31 & 16.3 \\
\hline Field worker & 26 & 13.7 \\
\hline Driver & 15 & 7.9 \\
\hline Tradesman & 12 & 6.3 \\
\hline Unemployed & 10 & 5.3 \\
\hline Other & 27 & 14.2 \\
\hline
\end{tabular}

RTC $(89,46.8 \%)$ represented the most common mechanism of injury requiring orthopaedic ward admission, followed by falls $(60,31.6 \%)$ and infections (14, 7.4\%). (Table 4) Motorized vehicles versus pedestrians represented $28.1 \%$ (25/89) of the RTC group. The majority of RTCs $(61,68.5 \%)$ were motorcycle-related (motorcycle driver/passenger or pedestrian struck by motorcycle). The most common reason for admission was fracture $(148,77.9 \%)$, followed by infection $(16,8.4 \%)$ and removal of implant (ROI) $(8,4.2 \%)$. 
Table 4

Injury Characteristics (Mechanism, Reason for admission) $(n=190)$

\begin{tabular}{|lll|}
\hline Variable & $\mathbf{n}$ & $\%$ \\
\hline Mechanism of Injury & & \\
\hline RTC & 89 & 46.8 \\
\hline Motorcycle & 47 & 52.8 \\
\hline Pedestrian & 25 & 28.1 \\
\hline Car & 11 & 12.4 \\
\hline Truck & 3 & 3.4 \\
\hline Bicycle & 2 & 2.2 \\
\hline Bus & 1 & 1.1 \\
\hline Falls & 60 & 31.6 \\
\hline Infection & 14 & 7.4 \\
\hline Tumor/Mass & 10 & 5.3 \\
\hline Assault & 7 & 3.7 \\
\hline Crush Injury & 6 & 3.2 \\
\hline Other & 4 & 2.1 \\
\hline Reason for Admission & & \\
\hline Fracture & 148 & 77.9 \\
\hline Infection & 16 & 8.4 \\
\hline Removal of Implant & 8 & 4.2 \\
\hline Tumor/Mass & 7 & 3.7 \\
\hline Dislocation & 4 & 2.1 \\
\hline Laceration & 3 & 1.6 \\
\hline Muscular Injury & 3 & 1.6 \\
\hline Gout & & 0.5 \\
\hline
\end{tabular}

Of the patients diagnosed with a fracture, 34.5\% (51) had at least one open fracture while $65.5 \%$ (97) had only closed fractures. Femur fractures were the most common injury $(62,31.0 \%)$, followed by tibia fractures $(27,13.5 \%)$, isolated fibula fractures $(23,11.5 \%)$, and foot fractures $(23,11.5 \%)$ (Table 5$)$. 
Table 5

AO/OTA Fracture Classification - Prospective Admissions $(n=200)$

\begin{tabular}{|c|c|c|c|}
\hline Fracture & AO/OTA Classification & $\mathbf{n}$ & $\%$ \\
\hline Femur & & 62 & $31.0 \%$ \\
\hline Trochanteric Region & $31 A$ & 13 & $21.0 \%$ \\
\hline Femoral Neck & $31 B$ & 12 & $19.4 \%$ \\
\hline Femoral Head & $31 C$ & 0 & $0.0 \%$ \\
\hline Diaphyseal-Simple & $32 A$ & 18 & $29.0 \%$ \\
\hline Diaphyseal - Wedge & $32 B$ & 10 & $16.1 \%$ \\
\hline Diaphyseal - Multi-fragmentary & $32 C$ & 3 & $4.8 \%$ \\
\hline Distal Extraarticular & $33 A$ & 2 & $3.2 \%$ \\
\hline Partial Articular & $33 B$ & 1 & $1.6 \%$ \\
\hline Complete Articular & $33 C$ & 2 & $3.2 \%$ \\
\hline Tibia & & 27 & $13.5 \%$ \\
\hline Proximal Articular & 41 & 5 & $18.5 \%$ \\
\hline Diaphyseal & 42 & 20 & $74.1 \%$ \\
\hline Distal Articular & 43 & 2 & $7.4 \%$ \\
\hline Fibula & & 23 & $11.5 \%$ \\
\hline Proximal Articular & $4 F 1$ & 4 & $17.4 \%$ \\
\hline Diaphyseal & $4 F 2$ & 18 & $78.3 \%$ \\
\hline Distal Articular & $4 F 3$ & 1 & $4.3 \%$ \\
\hline Foot & & 23 & $11.5 \%$ \\
\hline Metatarsal & 87 & 15 & $65.2 \%$ \\
\hline Phalanx & 88 & 6 & $26.1 \%$ \\
\hline Talus & 81 & 1 & $4.3 \%$ \\
\hline Foot Crush Injury & 89 & 1 & $4.3 \%$ \\
\hline Radius & & 12 & $6.0 \%$ \\
\hline Proximal Articular & $2 R 1$ & 0 & $0.0 \%$ \\
\hline Diaphyseal & $2 R 2$ & 6 & $50.0 \%$ \\
\hline Distal Articular & $2 R 3$ & 6 & $50.0 \%$ \\
\hline
\end{tabular}




\begin{tabular}{|c|c|c|c|}
\hline Fracture & AO/OTA Classification & $\mathbf{n}$ & $\%$ \\
\hline Ankle & & 11 & $5.5 \%$ \\
\hline Infra-syndesmotic Fibula Injury & $44 A$ & 0 & $0.0 \%$ \\
\hline Trans-syndesmotic Fibula Fracture & $44 B$ & 3 & $27.3 \%$ \\
\hline Supra-syndesmotic Fibula Fracture & $44 C$ & 8 & $72.7 \%$ \\
\hline Pelvis & & 9 & $4.5 \%$ \\
\hline Acetabulum & 62 & 4 & $44.4 \%$ \\
\hline Pelvic Ring & 61 & 5 & $55.6 \%$ \\
\hline Humerus & & 9 & $4.5 \%$ \\
\hline Proximal Articular & 11 & 2 & $22.2 \%$ \\
\hline Diaphyseal & 12 & 2 & $22.2 \%$ \\
\hline Distal Articular & 13 & 5 & $55.6 \%$ \\
\hline Hand & & 9 & $4.5 \%$ \\
\hline Metacarpal & 77 & 7 & $77.8 \%$ \\
\hline Phalanx & 78 & 1 & $11.1 \%$ \\
\hline Scaphoid & 72 & 1 & $11.1 \%$ \\
\hline Ulna & & 7 & $3.5 \%$ \\
\hline Proximal Articular & $2 U 1$ & 0 & $0.0 \%$ \\
\hline Diaphyseal & $2 U 2$ & 4 & $57.1 \%$ \\
\hline Distal Articular & $2 U 3$ & 3 & $42.9 \%$ \\
\hline Other & & 8 & $4.0 \%$ \\
\hline Patella & 34 & 5 & $62.5 \%$ \\
\hline Rib & 16 & 2 & $25.0 \%$ \\
\hline Clavicle & 15 & 1 & $12.5 \%$ \\
\hline
\end{tabular}

One-hundred twenty-four (83.8\%) fracture patients had a lower extremity fracture. Fifty-six (37.8\%) fracture patients sustained multiple fractures; thirty-three (22.3\%) patients had fractures involving multiple extremities. X-rays were available for 122/148 (82.4\%) fracture patients, who collectively sustained a total of 200 fractures. 
The average time from admission to surgical intervention was 4.2 days (range, 0 to 40 days, SD 6.2). Of the patients who were discharged during the study period, the mean hospital length of stay was 11.6 days and the median length of stay was 6 days (range, 1 to 46 days, SD 7.0). Few non-surgical patients were admitted during the study period (8/190, 4.2\%); the majority were pediatric patients with a mid-shaft femur fracture that were treated with Plaster of Paris casting. Among patients indicated for surgical intervention, less than half received definitive fracture treatment (Fig. 2).

\section{Retrospective Cohort}

From October 1, 2017 through April 30, 2018, 1,271 orthopaedic consultations were evaluated in the ED; this corresponded to an average of 6 consultations per day, 182 consultations per month, and 2,179 per year.

Over 81 consecutive clinic days from April 10, 2018 through August 1, 2018, 3,802 patients were evaluated in the outpatient orthopaedic clinic; this corresponded to an average of 47 patients per day, 235 patients per week, 939 patients per month, and 11,266 patients per year. A majority of clinic patients $61.3 \%(2,330)$ had some form of health insurance, while all other patients $(1,471)$ paid out of pocket. The out of pocket expense was approximately $\$ 2.20$; depending on the services provided, some were required to pay as much as $\$ 22.00$. As benchmark reference, the GDP per capita in Tanzania per week is $\$ 19.14$. (7)

During the 31 consecutive months from January 1, 2016 through July 31, 2018, 4,318 patients were admitted to the orthopaedic ward. This corresponded to an average of 139 patient admissions per month and 1,672 admissions per year. The kappa coefficient for retrospective data collection was 0.96 , indicating excellent inter-observer reliability between the two reviewers.

Based on the annualized data presented above, KCMC treated an average of 15,117 orthopaedic patients per year. Approximately $74.5 \%(11,266)$ were seen as outpatients in clinic, $14.4 \%(2,179)$ were treated and discharged from the ED, and $11.1 \%(1,672)$ were admitted to the inpatient orthopaedic ward. Relative to 2015 , ED consultations decreased by $35.1 \%$, while outpatient evaluations and inpatient admissions increased by $76.6 \%$ and $16.9 \%$, respectively. Between 2015 and 2018 , the overall number of musculoskeletal patients at KCMC increased by $35.3 \%$ (Table 6). 
Table 6

Retrospective Data - EMD Consultations, Orthopaedic Clinic Patients, and Orthopaedic Ward Admissions in 2015 and 2018

\begin{tabular}{|lccc|}
\hline Clinical Setting & $\mathbf{2 0 1 5}$ & $\mathbf{2 0 1 8}$ & Percentage Change \\
\hline EMD Consultations & 3358 & 2179 & $-35.1 \%$ \\
\hline Orthopaedic Clinic Patients & 6379 & 11266 & $+76.6 \%$ \\
\hline Orthopaedic Ward Admissions & 1430 & 1672 & $+16.9 \%$ \\
\hline $\begin{array}{l}\text { Total Patients } \\
\text { Legend: 2018 data represents annualized data from the corresponding retrospective data collection } \\
\text { periods. }\end{array}$ & $\mathbf{1 1 1 7 2}$ & $\mathbf{1 5 1 1 7}$ & $\mathbf{+ 3 5 . 3 \%}$ \\
\hline
\end{tabular}

\section{Discussion}

The need for timely, safe, and affordable basic surgical services in Sub-Saharan Africa is clear. We found that over $95 \%$ of prospective patients admitted to the orthopaedic ward at KCMC were indicated for operative intervention; this is in line with our previous findings.(4) In $2015,57.9 \%$ of surgical candidates were taken to the operating room for treatment. However, this group included both patients who received temporizing treatments such as bedside irrigation or traction pin placement and those that received definitive treatment (ORIF, intramedullary nailing or removal of implant). In the current study, we subcategorized patients into two groups: temporizing treatment and definitive fixation. While over $70 \%$ of surgical candidates were taken to the operating room for any surgical treatment, only $44.5 \%$ of the total received definitive treatment for their fracture. We believe that by excluding procedures that did not provide definitive treatment, this percentage is a more accurate reflection of the current surgical system's ability to definitively treat orthopaedic patients.

Several surgical system constraints prevent the delivery of definite fracture treatment including: 1) the patient's inability to pay for surgery, 2) a lack of a steady supply of expensive orthopaedic implants and 3 ) an inadequate number of operating theaters, which compromises surgical capacity. The lack of affordability is a major constraint. For the operative procedure alone, the out of pocket cost at KCMC is over $\$ 100$ (230,000 TZS as per the foreign exchange rate on $5 / 26 / 2020)$, significantly more than the average Tanzanian monthly income. Additional fees for implants, imaging, medications, and hospital stay financially overwhelm patients and their family. Our group's previous work at KCMC revealed that nearly $75 \%$ of orthopaedic patients reported catastrophic healthcare expenditures when seeking care for their injuries - without making care affordable, definitive fracture treatment will never be readily available. $(8,9)$

With local government's inability to dedicate required resources to improve road safety laws, infrastructure and road safety education, injuries from RTCs will continue to rise as motorized transport 
becomes the mainstay in the developing world. As in 2015, RTC was the most common mechanism of injury for admitted patients in the current study. Motorcycles, a very common form of inexpensive transport, represented over two-thirds of RTC injuries; patients sustained their injuries either as a driver, passenger or pedestrian. The majority of patients were admitted for fracture care, with nearly $84 \%$ having at least one lower extremity fracture and more than $75 \%$ were male. Untreated lower extremity fractures confer a great deal of long-term morbidity as the lack of infrastructure result in most LMICs being nonwheelchair accessible. The high prevalence of injured males significantly impacts the Tanzanian economy as most patients do not return to the work force without definitive surgical fixation.(9)

Analysis of the retrospective data revealed a $35 \%$ increase in the overall orthopaedic disease burden between 2015 and 2018. When assessing the individual components, the ED exhibited a $35.1 \%$ decrease in consultations, the outpatient clinic demonstrated a $76.6 \%$ increase in the patients evaluated and orthopaedic ward admissions increased by $16.9 \%$. These findings reflect an increase in clinic capacity; KCMC increased the frequency of outpatient clinics from two weekly in 2015 to five weekly in 2018. With the increased outpatient clinic capacity, many patients historically seen in the ED were redirected to the orthopaedic outpatient clinic for evaluation. Over the study period, 1,179 fewer patients were evaluated in the ED in 2018 compared to 2015. Even if these patients were preferentially seen in the outpatient clinic, this transfer did not account for the additional 3,700 patients seen in 2018 compared to 2015. The exhibited increase in inpatient ward admissions represents the overall increased demand for orthopaedic services - the musculoskeletal disease burden at $\mathrm{KCMC}$ is persistent and growing.

Potential non-epidemiological causes for the increase in musculoskeletal disease burden at KCMC were considered. However, there were no closures of hospitals in the region that provided orthopaedic surgery, nor was there any significant improvement in road infrastructure in the area - both of which might have resulted in an increased burden of disease presenting to KCMC.

Our secondary analysis demonstrated that of the 3,802 patients seen as an outpatient, $61.3 \%(2,330)$ had some form of health insurance. This was an increase from 2015, where only $42.6 \%(227 / 532)$ of patients were insured. This is a favorable trend for Tanzania, where Universal Health Coverage (UHC) has been a goal since the World Health Organization advocated for UHC in every country by 2030 . However, these percentages far exceed the level of national health insurance coverage in Tanzania, reported to be 16$32 \% .(10,11)$ Other studies support the disproportionately high health insurance utilization among patients who voluntarily seek surgical services. $(8,12)$ In our study, nearly $40 \%$ of patients paid out of pocket for outpatient services, and it is speculated that potential patients without insurance may avoid seeking care due to perceived or real costs associated with treatment. Regardless, the Tanzanian Government has reaffirmed its commitment to UHC, announcing new insurance packages for the National Health Insurance Fund (NHIF), with the stated goal of increasing enrollment to over $50 \%$ by the end of 2020.(11)

Among the strengths of this study is that it provides actual country specific data on the burden of musculoskeletal disease in a LMIC. Such data remains scarce, with most burden of surgical disease 
estimates extrapolated from indirect methods, such as demographic surveillance systems, household surveys and a combination of models. $(13,14)$ An important limitation to this study is that it only includes patients that present to a tertiary care center - patients in the region that sustain orthopaedic injuries may never seek care due to system constraints (lack of transportation, travel distance and unaffordability). In addition, alternative healers continue to be common in northern Tanzania. Other Sub-Saharan African studies have reported that as many as $85 \%$ of people who suffer an acute fracture first visit alternative healers (including traditional "bone setters") for care.(15) Further work has been undertaken by our research team to more accurately characterize the utilization and role of alternative healers in northern Tanzania. Identifying ways to collaborate with alternative healers will aid in the awareness of allopathic medical centers and the provision of services.(16)

Regarding the retrospective arm of this study, our conclusions were limited by patient record availability. Shortcomings in record keeping in this setting usually lead to the omission of patients and/or cases, rather than the inclusion of patients and cases that did not exist. The ultimate result of these data shortcomings would be the underestimation of disease burden. For this reason, we feel comfortable reporting the increasing trend in musculoskeletal disease burden in this region.

This study also excluded orthopaedic spine patients. At the time of this study, resources were unavailable at KCMC to treat these patients surgically. The inclusion of spine injured patients would have increased the total number of musculoskeletal patients seen at KCMC as well as significantly increase the number of patients who did not receive surgery but for whom surgery was indicated. In addition, the definition of "definitive treatment" was subjective. If intramedullary nailing or ORIF was performed, the procedure was deemed to be definitive, but the fixation technique, surgical approach, implant used, or other technical criteria were not used to evaluate the reconstruction. Furthermore, definitive treatment does not guarantee a favorable outcome; preliminary investigation into post-operative rehabilitation services available via $\mathrm{KCMC}$ have shown this to be an area in need of substantial development. With known resource limitations in implant availability, the percentage of orthopaedic injuries effectively treated with surgery is likely lower than our calculations suggest.

Surgical candidates who did not receive surgery received skeletal traction. While we believe this treatment option likely leads to long-term deleterious outcomes, we have as of yet been unable to design a strategy and protocol to capture this data, which can be elusive due to prohibitively poor follow up in these patients. Collecting this data remains an important goal of our research team.

\section{Conclusions}

The Global Burden of Disease 2017 study predicts a $26.0 \%$ increase in worldwide road traffic injuries by 2030; this study supports this projection.(17) The burden of orthopaedic surgical disease seen at KCMC is dominated by trauma and is increasing at a rate similar to or above that of global estimates.(4) Significantly fewer available resources leaves a growing burden of neglected orthopaedic surgical 
disease. Without new strategies to address this worsening situation, the discrepancy between supply and demand for musculoskeletal surgical care in the developing world will continue to grow.

Collaborative efforts are underway to develop an Orthopaedic Center of Excellence at KCMC. Volunteer surgeons at leading international academic institutions will provide year-round surgical services, specialty training, sustainable access to implants, and a mechanism by which to address post-operative complications. $(18,19)$ This venture's financial structure is devised to deliver democratized orthopaedic care - patients would have access to care regardless of their ability to pay. The foundation of this longterm partnership with $\mathrm{KCMC}$ is based on education at every level - a critical component of creating a sustainable solution.

\section{List Of Abbreviations}

road traffic crashes (RTCs)

Kilimanjaro Christian Medical Center (KCMC)

low- and middle-income countries (LMIC)

United States of America (USA)

emergency department (ED)

open reduction and internal fixation (ORIF)

removal of implant (ROI)

Universal Health Coverage (UHC)

National Health Insurance Fund (NHIF)

\section{Declarations}

\section{Ethics approval and consent to participate}

This study received Kilimanjaro Christian Medical Centre Clinical Research Ethical Review Committee approval prior to data collection and analysis. As all clinical data was de-identified and no protected health information for any patient was disclosed, informed consent was waived. Consent for publication

Not applicable.

\section{Availability of data and materials}

The datasets used and/or analyzed during the current study are available from the corresponding author on reasonable request. 


\section{Competing interests}

NS reports consultancy compensation from Zimmer Biomet, Smith and Nephew, Medacta, Microport, SCA, and Elsevier. The remaining authors declare that they have no relevant competing interests pertaining to this research study.

\section{Funding}

This study received logistics funding from the Global Engagement Fund of the University of Pennsylvania.

\section{Author's contributions}

All authors have contributed meaningfully to the final manuscript.

\section{Acknowledgements}

Not Applicable

\section{Author's Information}

Not Applicable

\section{References}

1. Global status report on road safety 2018. World Health Organization, Geneva; 2018.

2. Naghavi M, Abajobir AA, Abbafati C, Abbas KM, Abd-Allah F, Abera SF, et al. Global, regional, and national age-sex specific mortality for 264 causes of death, 1980-2016: a systematic analysis for the Global Burden of Disease Study 2016. The Lancet. 2017 Sep 16;390(10100):1151-210.

3. Global Surgery Map I COSECSA [Internet]. [cited 2020 May 25]. Available from: http://www.cosecsa.org/global-surgery-map

4. Premkumar A, Massawe HH, Mshabaha DJ, Foran JRH, Sheth NP. The burden of orthopaedic disease presenting to a referral hospital in northern Tanzania. Glob Surg. 2016;2(1):70-5.

5. Premkumar A, Ying X, Mack Hardaker W, Massawe HH, Mshahaba DJ, Mandari F, et al. Access to Orthopaedic Surgical Care in Northern Tanzania: A Modelling Study. World J Surg. 2018 Oct 1;42(10):3081-8.

6. Meinberg EG, Agel J, Roberts CS, Karam MD, Kellam JF. Fracture and Dislocation Classification Compendium-2018. Journal of Orthopaedic Trauma. 2018 Jan;32(Supplement 1):S1-170.

7. The World Bank. GDP per capita (current US\$) - Tanzania. 2015-2018 [Internet]. [cited 2020 May 25]. Available from: https://data.worldbank.org/indicator/NY.GDP.PCAP.CD? end $=2018 \&$ locations $=$ TZ\&start $=2015$ 
8. Rajaguru PP, Jusabani MA, Massawe H, Temu R, Sheth NP. Understanding surgical care delivery in Sub-Saharan Africa: a cross-sectional analysis of surgical volume, operations, and financing at a tertiary referral hospital in rural Tanzania. Global Health Research and Policy. 2019 Oct 26;4(1):30.

9. Davey S, Bulat E, Massawe H, Pallangyo A, Premkumar A, Sheth N. The Economic Burden of Nonfatal Musculoskeletal Injuries in Northeastern Tanzania. Annals of Global Health. 2019 Mar 4;85(1):23.

10. Amu H, Dickson KS, Kumi-Kyereme A, Darteh EKM. Understanding variations in health insurance coverage in Ghana, Kenya, Nigeria, and Tanzania: Evidence from demographic and health surveys. PLOS ONE. 2018 Aug 6;13(8):e0201833.

11. Lugongo B. NHIF set ambitious enrollment target. Daily News (Tanzania Standard Newspapers Ltd) [Internet]. 2019 Nov 28 [cited 2020 May 25]; Available from: https://www.dailynews.co.tz/news/2019-11-285ddf70dd71e04.aspx

12. Mills A, Ataguba JE, Akazili J, Borghi J, Garshong B, Makawia S, et al. Equity in financing and use of health care in Ghana, South Africa, and Tanzania: implications for paths to universal coverage. The Lancet. 2012 Jul 14;380(9837):126-33.

13. Petroze R, Nzayisenga A, Calland J. Surgical Volumes at the District Hospital: A Retrospective Review of National Data in Rwanda. East and Central African Journal of Surgery. 2011;16(2):102-11.

14. Weiser TG, Regenbogen SE, Thompson KD, Haynes AB, Lipsitz SR, Berry WR, et al. An estimation of the global volume of surgery: a modelling strategy based on available data. Lancet. $2008 \mathrm{Jul}$ 12;372(9633):139-44.

15. Omololu A, Ogunlade S, Gopaldasani V. The Practice of Traditional Bonesetting: Training Algorithm. Clinical Orthopaedics and Related Research. 2008 Oct;466(10):2392-8.

16. Card E, Obayemi J, Shirima O, Lazaro M, Massawe H, Sheth N. Practices and perspectives of traditional bone setters in northern Tanzania. Annals of Global Health (Accepted). 2020;

17. GBD Results Tool | GHDx [Internet]. [cited 2020 May 25]. Available from: http://ghdx.healthdata.org/gbd-results-tool

18. Sheth NP, Hardaker WM, Zakielarz KS, Rudolph M, Massawe H, Levin LS, et al. Developing Sustainable Orthopaedic Care in Northern Tanzania: An International Collaboration. Journal of Orthopaedic Trauma. 2018 Oct;32(7):S25-28.

19. Sheth N, Premkumar A. University of Pennsylvania Leads Collaboration to Create a Sustainable Solution for Orthopaedics in Sub-Saharan Africa. AAOS Now [Internet]. 2020 Feb 1 [cited 2020 May 25]; Available from: https://www.aaos.org/aaosnow/2020/feb/international/international02/

\section{Figures}




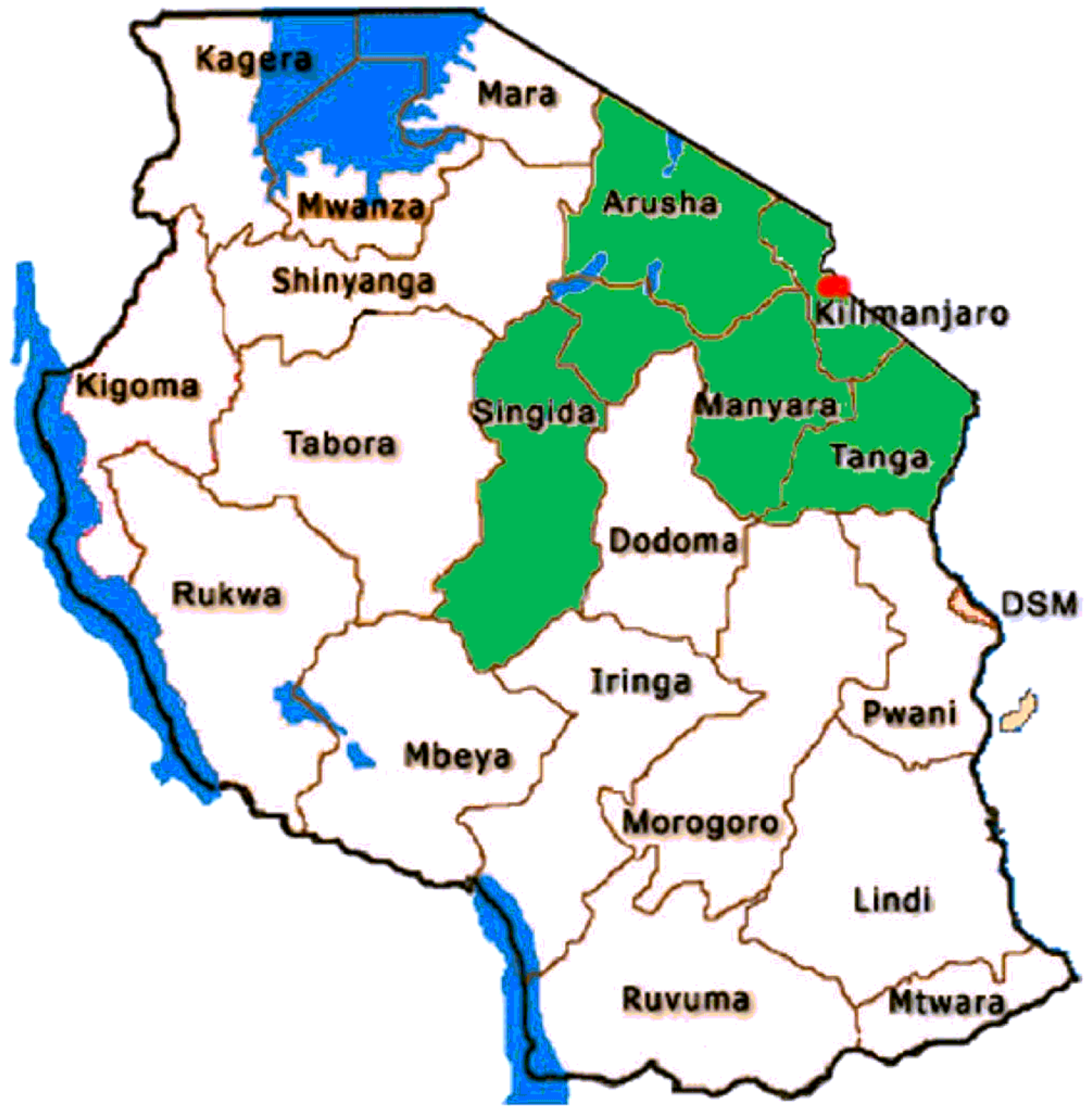

Figure 1

$\mathrm{KCMC}$ is the tertiary referral hospital for five regions in northern Tanzania: Arusha, Kilimanjaro, Manyara, Singida, and Tanga (Image from: Sheth NP, Hardaker WM, Zakielarz KS, et al. Developing Sustainable Orthopaedic Care in Northern Tanzania: An International Collaboration. Journal of Orthopaedic Trauma. 2018;32:S25.) 


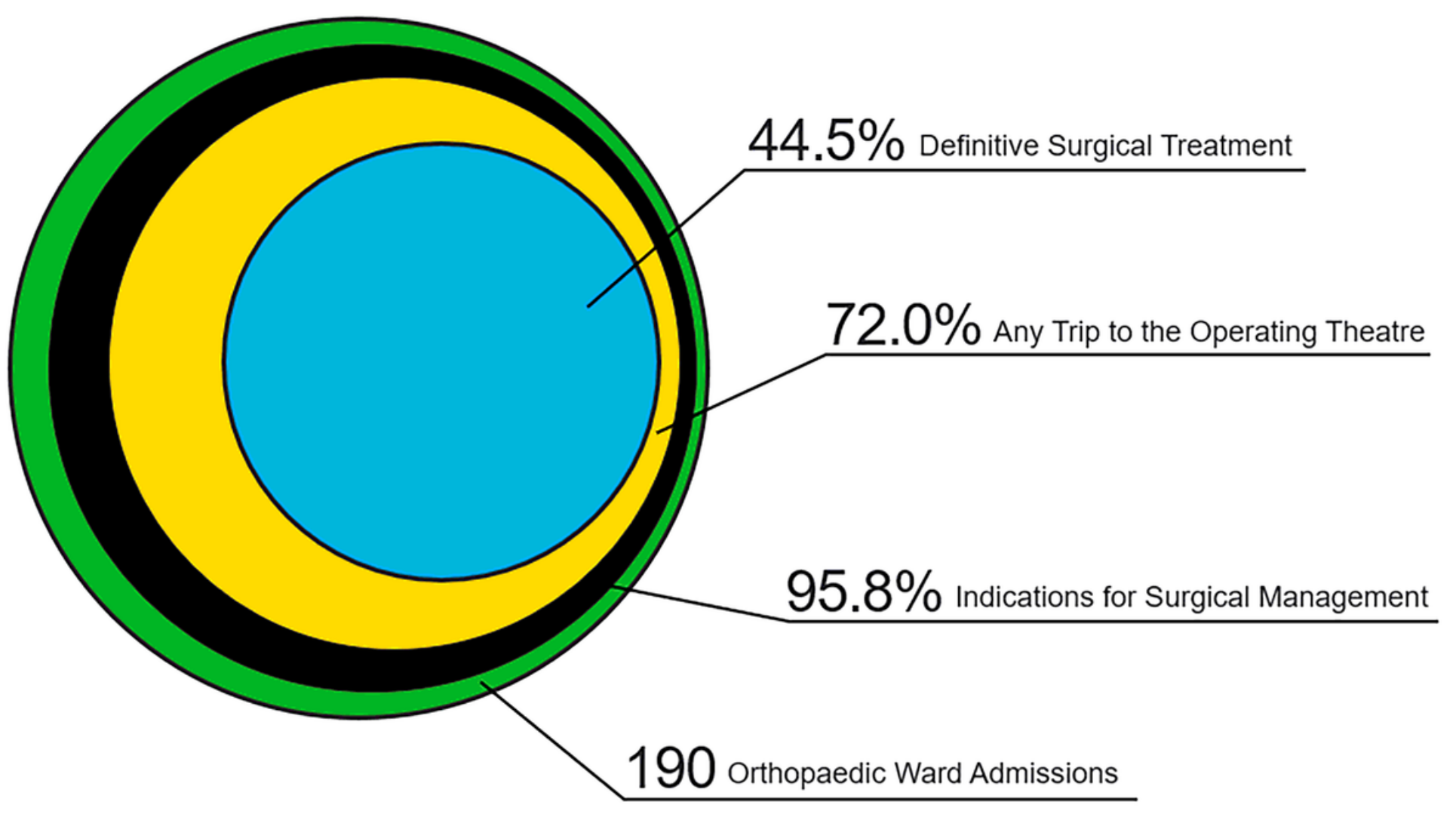

Figure 2

Prospective Admissions with indications for Surgical Management: Any Trip to the Operating Room versus Definitive Treatment 